\title{
Ativação do patrimônio biocultural do cerrado e turismo comunitário: notas metodológicas a partir do caso de Penedo (São Desidério, Bahia, Brasil)
}

\author{
Activation of the biocultural heritage of the cerrado \\ and community tourism: methodological notes from the \\ case of Penedo (Sao Desidério, Bahia, Brazil)
}

Paulo Roberto Baqueiro Brandão*

Fecha de recibido: 27 de mayo de 2020

Fecha de aceptado: 28 de agosto de 2020

\section{Resumo}

Este texto parte de um questionamento: quais são os caminhos metodológicos para o desenvolvimento de uma proposta de turismo comunitário em pequenas localidades a partir da ativação do patrimônio biocultural e sob a inspiração do Buen Vivir como filosofia de vida e práxis territorial? Diante dessa indagação, pretende-se apresentar uma proposta metodológica para implantação de iniciativa de turismo comunitário a partir da ativação do patrimônio biocultural do cerrado, considerando a possibilidade da sua realização em Penedo, localidade do município baiano de São Desidério (Brasil). Para tanto, o artigo segue um roteiro que exprime a necessidade de (a) desenvolver um arcabouço teórico-conceitual orientador do trabalho de investigação-intervenção a ser desenvolvido, (b) caracterizar a localidade objeto dessa ação cooperativa e (c) apontar ferramentas de pesquisa para a identificação das territorialidades e temporalidades locais, bem como dos principais problemas e riscos que afetam o povoado de Penedo, suas causas e efeitos.

Palavras-chaves: Buen Vivir; Práxis territorial; Patrimônio biocultural; Turismo comunitário; Penedo (São Desidério, Brasil).

* Universidade Federal do Oeste da Bahia, Brasil; Grupo de Pesquisa Dinâmicas Espaciais e Desenvolvimento Territorial (GRUDET/UFOB).Correo electrónico: paulo.baqueiro@ufob.edu.br. 


\section{Abstract}

This text comes from a questioning: What are the methodological paths towards the development of a proposal of community tourism in small village coming from the biocultural patrimony activation and under the inspiration of the Buen Vivir as a life philosophy and territorial praxis? Upon this enquiry, it is aimed to present a methodological proposal for the implementation of the community tourism initiative as of the cerrado's biocultural patrimony activation, regarding the possibility of its execution in Penedo, a locality in the county of São Desidério (Brazil). For this purpose, the article follows a guideline that conveys the need to (a) develop a concept-theoretical framework which will orient the work of investigation-intervention to be developed, (b) characterize the location which is object of this cooperative action and (c) point out the research tools regarding the identification of local territorialities and temporalities, as well as the identification of main risks and problems that affect the village of Penedo, its main causes and effects.

Key words: Buen Vivir; Territorial Praxis; Biocultural patromony; Community tourism; Penedo (São Desiderio, Brazil).

\section{Resumen}

Activación del patrimonio biocultural del cerrado y turismo comunitario: notas metodológicas a partir del caso de Penedo (São Desidério, Bahia, Brasil)

Con este texto se busca contestar una pregunta: ¿cuáles son las trayectorias metodológicas para el desarrollo de una propuesta de turismo comunitário en pequeñas localidades apartir de la activación del patrimonio biocultural e bajo la inspiración del Buen Vivir como filosofía de vida y praxis territorial? En este contexto, la pretensión es presentar una propuesta metodológica para apoyar el desarrollo del turismo comunitário apartir de la activación del patrimonio biocultural del cerrado en el pueblo de Penedo, ubicado en el municipio bahiano de São Desidério (Brasil). Para ello, el artículo está estructurado con las siguientes secciones: (a) un examen teórico-conceptual de ese trabajo de investigaciónintervención, (b) la caracterización de la localidad objeto de esa acción cooperativa y (c) hacer reflexiones acerca de las herramientas de investigación para la identificación de las territorialidades y temporalidades locales, los principales problemas y riesgos que afectan a la comunidad de Penedo, sus causas y efectos.

Palabras clave: Buen Vivir; Praxis territorial; Patrimonio biocultural; Turismo comunitário; Penedo (São Desidério, Brasil).

\section{Introdução}

A natureza predatória do neoliberalismo tem produzido efeitos devastadores em regiões onde tal paradigma político-econômico vem sendo experimentado. Do 
ponto de vista das sociedades, o que se vê é o aprofundamento da desigualdade, com ampliação do quadro de pobreza e disjunção crescente dos grupos sociais mais atingidos por tal desequilíbrio do direito à dignidade, a manipulação midiática, entorpecedora e alienante, e o controle social policialesco massivo, para evitar que a perversidade dessa pauta programática seja denunciada por grupos dissidentes.

Na maioria dos países da América Latina, por exemplo, o breve período sob a gestão de governos de ascendência popular tem sido sucedido por uma verdadeira avalanche conservadora, que (re)introduz uma agenda político-econômica baseada na privatização da economia - o que inclui bens e serviços públicos essenciais - e plena abertura dos mercados ao capital estrangeiro. Assim, a despeito do estrondoso fracasso já vivenciado em décadas passadas, a reconstrução do Estado neoliberal (Harvey, 2005) é uma realidade em diversos países latinoamericanos.

Contudo, a nova ofensiva conservadora não se dá sem reação. De um lado, os movimentos contestatórios ganham substância com seus vigorosos protestos e pautas reivindicatórias progressistas, ao tempo em que iniciativas emancipatórias e coletivas - protagonizadas pelas gentes comuns do campo e da cidade - que emergiram ou passaram a ser reconhecidas no período precedente ao atual demonstram, de forma inequívoca, que é possível vislumbrar uma alternativa aos infrutíferos modelos de desenvolvimento até então vigentes.

Dentre muitas dessas iniciativas que vicejam em toda a América Latina, o turismo comunitário aparece como uma prática com capacidade suficiente para potencializar relações localmente situadas, harmônicas e duradouras entre comunidade e natureza, assentadas no reconhecimento do território por seu valor de uso e com ênfase na ativação do patrimônio biocultural, o que incide na valorização da cosmovisão e dos saberes-fazeres das gentes comuns.

No entanto, por ser o turismo uma prática ainda muito identificada com perspectivas ostensivamente economicistas, segundo as quais o espaço deva ser produzido e consumido sob lógicas de mercado (Brandão, 2014), há que se indagar: quais são os caminhos metodológicos para o desenvolvimento de uma proposta de turismo comunitário em pequenas localidades a partir da ativação do patrimônio biocultural e sob a inspiração do Buen Vivir como filosofia de vida e práxis territorial?

Diante de tal indagação, pretende-se, por meio deste escrito, apresentar uma proposta metodológica para implantação de iniciativa de turismo comunitário a partir da ativação do patrimônio biocultural do domínio de natureza do cerrado, considerando a possibilidade da sua realização no povoado de Penedo, município de São Desidério (Bahia, Brasil).

Para tanto, este texto segue um roteiro que exprime a necessidade de (a) desenvolver um arcabouço teórico-conceitual orientador do trabalho de 
investigação-intervenção a ser desenvolvido, (b) caracterizar a localidade objeto dessa ação cooperativa e (c) apontar ferramentas de pesquisa para a identificação das territorialidades e temporalidades locais, bem como dos principais problemas e riscos que afetam o povoado de Penedo, suas causas e efeitos.

\section{Os elementos teórico-conceituais de apoio à metodologia}

Em uma perspectiva teórico-metodológica, este projeto está vinculado a abordagens da Teoria Crítica, em especial àquelas produzidas no seio da Geografia (Pignante, Dansero e Loda, 2015; Santos, 2002, 2008; Saquet, 2015, 2019), e dos Métodos Participativos (Diez, 2014, 2018a, 2018b; Freire, 1982, 2013), com ênfase na Pesquisa-Ação Participativa (Fals, 1999). Além disso, ao estabelecer uma aproximação com iniciativas baseadas na cosmovisão e experiências de comunidades, busca-se uma filiação epistemológica com o chamado Buen Vivir (Schavelzon, 2015; Acosta, 2016).

Destarte, como horizonte utópico para o modelo de transformação pelo qual se pretende propugnar, esta proposta de investigação-intervenção está afiliada à concepção de Buen Vivir, buscando, assim, adotar uma perspectiva decolonial de reflexão crítica, mas, principalmente, assumir uma forma de atuação propositiva que emparelha, "ombro a ombro", comunidade e universidade em "uma interfaceinteração mais intensa entre intelectualidade-ciência e cotidianidade-saber-arte, numa práxis de transformação territorial em favor das necessidades e anseios do povo" (Saquet, 2015: 126).

Importante salientar que não se trata de uma tentativa de transplante puro e simples de uma filosofia de vida surgida em um contexto geográfico-histórico singular (regiões andinas) e de tradição multissecular para uma realidade absolutamente distinta, como a do povoado de Penedo. Ao contrário, o que se pretende é buscar inspiração para mobilizar e articular conhecimentos locais, direcionando-os e confrontando-os para/com uma epistême que propõe um modelo substantivado nas horizontalidades, na prevalência dos desígnios de uma ordem local (Santos, 2002) e que está posicionada em absoluta oposição à opção neoliberal de desenvolvimento, para, a partir daí, extrair como síntese um irreversível movimento rumo à construção de sujeitos eco-sócio-políticos localmente situados.

Embora o chamado Buen Vivir ${ }^{1}$ (ou sumak kawsay, em língua quéchua) tenha sido construído como práxis a partir das tradições multisseculares dos povos originários andinos, a centralidade atual que ocupa nos debates sobre alternativas aos atuais modelos de desenvolvimento é fruto das recentes iniciativas de

\footnotetext{
Ao longo deste escrito, opta-se pelo uso do termo em espanhol, evitando-se, assim, todos os possíveis prejuízos que uma tradução livre do termo para o português possa causar quanto à compreensão do seu sentido original.
} 
enfretamento ao neoliberalismo em regiões periféricas da atual economia-mundo capitalista e da sua incorporação como paradigma para a definição de políticas públicas, tendo sido incorporado, nos casos do Equador e Bolívia, como elemento medular das constituições dos respectivos países.

O Buen Vivir é uma filosofia de vida em construção e, ainda que, como tal, não tenha sedimentado uma "trilha predeterminada" (Acosta, 2016: 49), é possível assim concebê-lo:

Com sua proposta de harmonia com a Natureza, reciprocidade, relacionalidade, complementaridade e solidariedade entre os indivíduos e comunidades, com sua oposição ao conceito de acumulação perpétua, com seu regresso a valores de uso, o Bem Viver, uma ideia em construção, livre de preconceitos, abre as portas para a formulação de visões alternativas de vida (p. 41).

(...)

O Bem Viver [...] se nutre da imperiosa necessidade de impulsionar uma vida harmônica entre os seres humanos e deles com a Natureza: uma vida centrada na autossuficiência e na autogestão dos seres humanos vivendo em comunidade (p. 47).

Trata-se, portanto, de um paradigma baseado nos Direitos Humanos e da Natureza e na evocação de saberes ancestrais como elementos fundantes na construção de uma outra realidade, com ênfase na emancipação e autogestão, pós-desenvolvimentista e, portanto, livre das amarras epistemológicas e ontológicas da dicotomia Capitalismo-Socialismo.

No Brasil, o debate sobre Buen Vivir ainda repercute pouco. Entre os intelectuais de maior expressão no país, apenas Boff (2012: 61) faz algumas referências àquilo que chamou de "ética da suficiência para toda a comunidade e não apenas para o indivíduo", pressupondo "uma visão holística e integradora do ser humano inserido na grande comunidade terrenal que inclui, além do ser humano, o ar, água, os solos, as montanhas, as árvores e os animais, o Sol, a Lua e as estrelas".

De igual modo, nas políticas públicas brasileiras, a concepção de Buen Vivir foi e ainda é quase que sumariamente ignorada, não tendo qualquer expressividade. As exceções ficam por conta de alguns documentos produzidos por órgãos governamentais ou em parceria com universidades que versam sobre as temáticas da soberania e segurança alimentares e agroecologia (Sabourin e Niederle, 2017), além, por exemplo, de tímidas e implícitas citações contidas na Política Nacional de Desenvolvimento Sustentável dos Povos e Comunidades Tradicionais (Brasil, 2007) e nas duas versões do Plano Nacional de Agroecologia e Produção Orgânica (Brasil, 2013, 2016).

Para o desenvolvimento da metodologia ora explicitada, pretende-se atuar a partir de um roteiro que contemple, por um lado, um enfoque sobre os problemas e soluções locais e regionais e, por outro lado, que requeiram, na construção das respostas, o reconhecimento de processos políticos, educativos e culturais 
emancipatórios, prestando atenção ao conhecimento das gentes comuns, conforme propõe Fals (1999). Neste sentido, A Pesquisa-Ação Participante emerge como o paradigma investigativo a ser empregado, seja por ser base para a produção de uma ciência cidadã ou mesmo por "combinar la praxis con la ética, el conocimiento académico con la sabiduría popular, lo racional con lo existencial, lo sistemático con lo fractal” (Idem., p. 83).

As metodologias participativas servem, antes de tudo, para produzir conhecimento desde dentro das comunidades, a partir dos saberes que estas possuem de si mesmas e dos problemas que as envolvem (Bisio e Noboa, 2019). Mas esse conhecimento deve ser mobilizado para induzir transformações qualitativas duradouras e irredutíveis.

Segundo Fals (1999: 80) a Pesquisa-Ação Participativa é "una vivencia necesaria para progresar en democracia, como un complejo de actitudes y valores, y como un método de trabajo que dan sentido a la praxis en el terreno", sendo, pois, um modelo que pode alinhar comunidade e universidade na busca por transformação social.

Para a adequada realização da Pesquisa-Ação Participativa a partir do caso da comunidade que vive no povoado de Penedo, é imprescindível a adoção de procedimentos e ferramentas de pesquisa que convirjam com o caráter participativo e emancipatório da proposta, em especial na etapa de identificação e reconhecimento das idiossincrasias que caracterizam coletivamente os sujeitos e seus problemas. Neste caso, propõe-se o emprego do Mapeamento Participativo Comunitário, com ênfase no Mapeamento de Atores (Tapella, 2007; Algranati, Bruno e lotti, 2012) e na Cartografia Social (Arias, 2015; Diez, 2018a; 2018b).

Conforme assinalam Algranati, Bruno e lotti (2012: 4), o mapeamento de atores é "[...] una herramienta de indagación que permite identificar y caracterizar una diversidad de actores sociales existentes en el escenario de investigación". Também conhecido como sociograma (Tapella, 2007), o mapeamento de atores é uma ferramenta que permite ao investigador compreender uma dada realidade social, tratando não apenas de conhecer os sujeitos envolvidos na construção continuada de um território, mas também suas práticas, objetivos e estratégias de territorialização.

Nesse processo, é fundamental contar com a participação desses ditos atores na produção e sistematização dos dados, bem como considerar tal participação a partir da multiplicidade de sujeitos envolvidos na construção do território, o que implica em auscultar a comunidade, os representantes de entidades públicas e empresas privadas, além dos beneficiários e usuários diretos do território.

Por outro lado, há que se ter em conta que o mapeamento de atores se faz a partir de diferentes abordagens, variando segundo aquilo que se deseja colocar em relevo (Algranati, Bruno e lotti, 2012). Assim, considera-se que, para o caso em evidência (o povoado de Penedo), a forma mais adequada de mapeamento é por 
meio da Cartografia Social, permitindo o alcance horizontal (uma quantidade maior de sujeitos) e vertical (coleta de uma maior amplitude de dados) de modo mais proeminente.

Uma premissa essencial para a compreensão da cartografia social é ter em conta que "Mapear es una práctica, una acción, un modo de abordar territorios sociales, subjetivos, geográficos y el mapa es una herramienta que se cristaliza en diversos formatos y se abre a la participación" (Ares e Risler, 2013: 72). Neste sentido, a produção de uma cartografia social evoca uma ação coletiva e participativa, na qual os atores-construtores do território representam-no e interpretam-no segundo suas lógicas e visões de mundo.

Segundo Arias (2015), diferentemente do mapeamento técnico, a cartografia social é produzida a partir de uma perspectiva coletiva, participativa e consensual e sua elaboração depende de uma relação articulada entre a experiência comunitária e o saber científico.

Quanto à base conceitual mais elementar da pesquisa-cooperação, nesta proposta, o território assume centralidade como conceito geográfico, posto que se pretenda enfatizar os enlaces entre a comunidade e a terra, que, aqui, não deve ser considerada apenas como substrato para a produção agrícola, mas também como suporte à vida. Desta forma, é fundamental compreender tal relação, tanto no que se refere às formas de apropriação material, abordando os processos históricos de reprodução social e econômica, quanto no que tange à apropriação simbólica e à construção da identidade em âmbito comunitário.

Ademais, vale frisar, conforme apontado por Pignante, Dansero e Lorda (2015), que a Geografia tem aportado um considerável arcabouço de contribuições ao debate sobre cooperação para o desenvolvimento, principalmente, por meio da abordagem territorial.

O território é um elemento geográfico cujo significado epistemológico e ontológico está no fato de ser, ao mesmo tempo, uma instância espacial de poder, um produto social historicamente definido, relacional, multiescalar e multidimensional. Essas relações se configuram por meio de dominação e influência exercidas por um determinado indivíduo, grupo ou entidade sobre os demais. A esses se lhe denominam atores ou agentes.

Como instância espacial de poder, o território é o locus de relações sociais que tem na tentativa ou na efetivação da dominação e/ou apropriação do espaço a sua principal razão de ser. Conforme explica Montañez (2001: 20):

[...] cuando designamos un territorio siempre estamos asumiendo, aun de manera implícita, la existencia de un espacio geográfico y de un sujeto que ejerce sobre él cierto dominio, una relación de poder, una calidad de poseedor o una facultad de apropriación. La relación de pertenencia o apropriación no se refiere sólo a vinculos de propiedad sino también a aquellos lazos subjetivos de identidad y afecto 
existentes entre el sujeto y su territorio. Ese sujeto individual o colectivo continen generalmente una porción de poder suficiente para incidir en la transformación de ese territorio. El territorio es, pues, el espacio geográfico revestido de las dimensiones política, identitaria o afectiva, o de todas ellas.

Assim, importa frisar que, ao assumir uma abordagem a partir da apreensão do conceito de território como elemento norteador do porvir rumo ao Buen Vivir, este projeto alinha-se à perspectiva da práxis territorial, conforme preconiza Saquet (2015, 2019). Para o autor, o território configura-se como um espaço "de (in)formação, partilha, reciprocidade, mobilização, luta, resistência políticocultural-ambiental, descolonização, conquista da autonomia decisória e de melhores condições de vida para e com o povo" (2015: 8, itálico no original). É, portanto, no/a partir do/pelo território que se consolida uma práxis da cooperação e solidariedade entre os sujeitos próximos geográfica e socialmente.

Nesta investigação-intervenção, a empiricização do território é feita a partir de uma abordagem que busca equacionar saberes populares e conhecimentos técnico-científicos com vistas à construção de uma proposta de turismo comunitário a partir do caso do povoado de Penedo, no município de São Desidério, cuja caracterização será apresentada a seguir.

\section{Breve caracterização de Penedo}

O povoado de Penedo está localizado no município de São Desidério, este que, por sua vez, compõe o Território de Identidade da Bacia do Rio Grande, no estado da

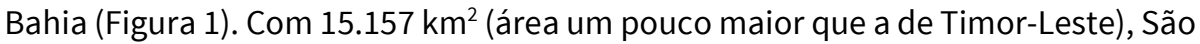
Desidério é o segundo maior município baiano em extensão territorial, onde vivem cerca de 33 mil habitantes, conforme estimativa do Instituto Brasileiro de Geografia e Estatística (IBGE), o que resulta em uma densidade demográfica de 2,22 hab/km².

Vale mencionar que, além dos cerca de 19 mil habitantes que residem na cidade, uma parcela considerável da população são-desideriana vive nas demais 159 nucleações urbanas e aglomerações rurais existentes, entre vilas e povoados, algumas das quais distantes mais de 150 quilômetros da sede municipal.

Inserido no domínio dos cerrados e graças à relativamente abundante disponibilidade hídrica e à predominância de relevo planáltico bastante aplainado na zona regionalmente conhecida como Gerais, São Desidédio possui forte aptidão para o desenvolvimento da agricultura mecanizada de alto rendimento.

Com efeito, devido aos fatores físico-ambientais anteriormente mencionados e aos investimentos estatais e privados, nos últimos quarenta anos, o município de São Desidério vivenciou vertiginosas transformações resultantes da formação de um espaço agrário altamente tecnicizado, processo similar ao que ocorreu nos demais municípios cuja parte do território é composta pelos Gerais. 


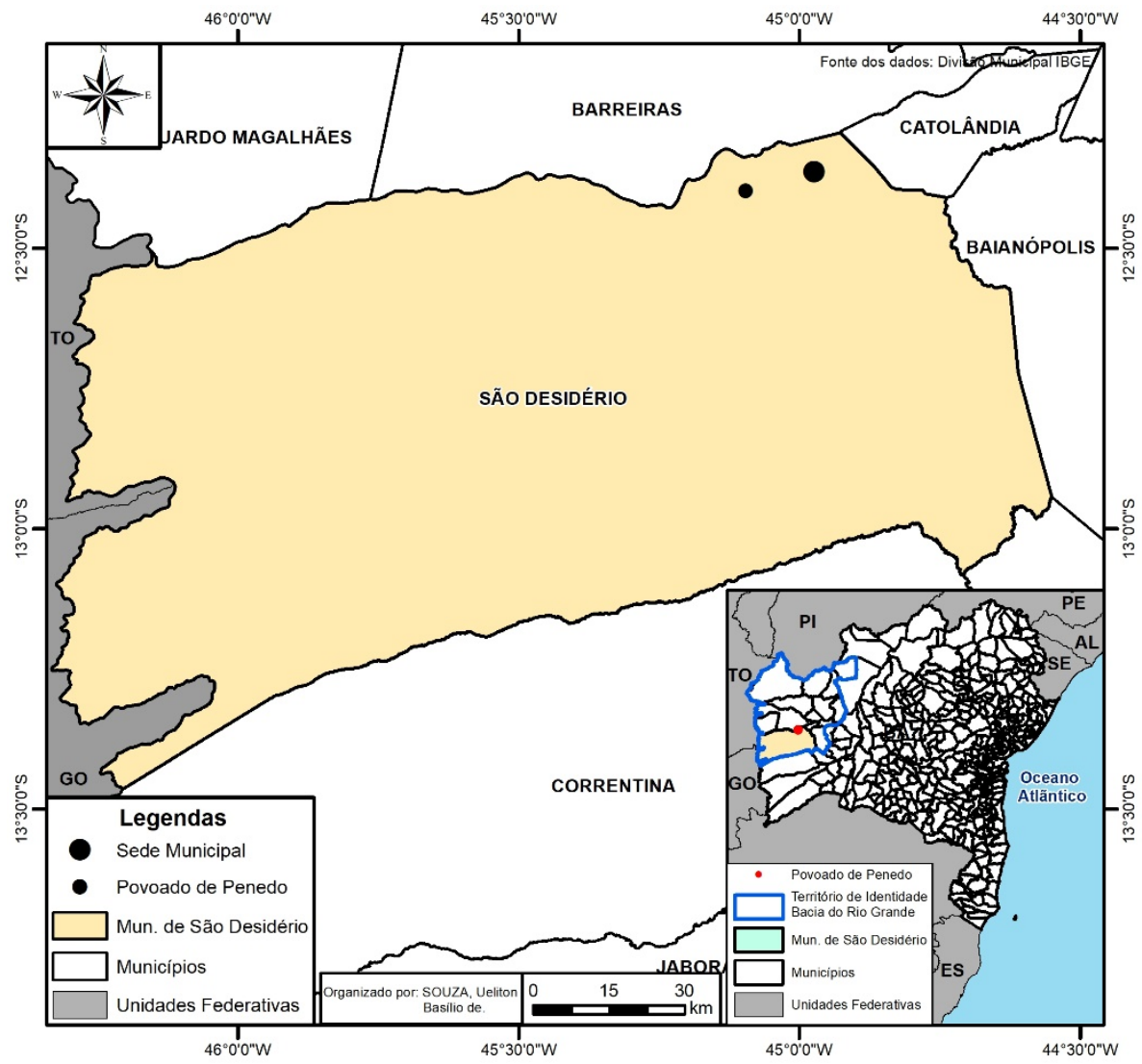

Figura 1. Localização do povoado de Penedo, município de São Desidério (Bahia, Brasil). Fonte: elaboração de Ueliton Basílio de Souza (equipe GRUDET/UFOB).

Neste sentido, atualmente, São Desidério é um dos municípios do país mais bem ranqueados quanto à contribuição do setor primário da economia na formação do Produto Interno Bruto, o que, no caso em tela, se dá pela predominância da produção de commodities agrícolas, tais como soja, algodão e milho e madeira, entre outros.

Contudo, esse modelo de desenvolvimento capitalista é a base para algumas contradições socioterritoriais que perduram há décadas em São Desidério, seja quanto ao relativo isolamento sociocultural, político e econômico das comunidades rurais, tradicionais e quilombolas, ou mesmo quanto aos conflitos socioambientais, principalmente aqueles ligados à apropriação da terra e aos usos da água, o que, no caso do Povoado de Penedo, diz respeito às implicações que afetam o Rio das Fêmeas, decorrentes da irrigação de grandes propriedades rurais 
e do barramento para funcionamento de uma pequena central hidrelétrica, com efeito na sensível redução da vazão do curso d'água nos períodos de estiagem.

No que tange a Penedo, esse povoado está localizado em ambas as margens do Rio das Fêmeas, em seu baixo curso, a oeste da cidade de São Desidério, cuja ligação é feita pela rodovia estadual BA-463 (pavimentada) e estrada rural (não pavimentada), estando distantes entre si por pouco mais de 25 quilômetros. Composto por algo em torno de 75 imóveis residenciais e uma edificação pública (a antiga Escola Municipal Florêncio José de Lima, atualmente desativada), o povoado possui uma população de cerca de 220 habitantes, segundo dados obtidos junto à Secretaria de Saúde local.

Quanto ao processo de formação territorial, não existem fontes escritas sobre Penedo. Desta forma, a estruturação de uma história territorial da localidade só é possível recorrendo-se aos relatos dos moradores locais, em especial, dos mais antigos, considerados guardiões da memória coletiva de Penedo. Destarte, segundo relatos coletados em auscutas nos momentos de formação de grupos focais com os residentes mais longevos, a localidade surgiu em meados de década de 1940, a partir da atração populacional exercida por um suposto eremita - que seria um clérigo alemão - fixado, não se sabe por qual motivo, em uma gruta de uma escarpa próxima cujo topônimo é justamente Boqueirão do Padre.

Esses primeiros moradores viviam em condições precárias, considerando o relativo isolamento ao qual estavam submetidos pela falta de via com leito carrocável e meios de transportes regulares que os ligassem à Barreiras, então sede municipal, ou São Desidério, que, à época, era uma própera vila barreirense. As formas de reprodução social estavam submetidas, portanto, a uma forte relação intracomunitária, ao tempo em que as formas de reprodução econômica eram realizadas a partir da venda do pequeno excedente da produção agrícola e de alguns subprodutos da cana-de-açúcar plantada nas pequenas propriedades, como a rapadura e aguardente, cuja comercialização, por sua vez, era feita na sede municipal e na vila, a partir da distribuição realizada em lombos de muares e equinos.

Exceto pelos sistemas de engenharia que foram introduzidos na/para a localidade ao longo das décadas precedentes, para oferta de energia eletrica e abertura de via de transporte, e pelo acesso - ainda que precário - às tecnologias de comunicação (sinal de televisão, telefonia móvel e internet), a comunidade segue vivendo sob os desígnios desse longo processo de inércia territorial, ao tempo em que a carência de serviços públicos vige desde à fundação até os dias hodiernos, como se verá a seguir.

À exceção das visitas das equipes do Programa Saúde da Família, os demais atendimentos são realizados, a depender da gravidade, no posto de saúde localizado no povoado vizinho do Sítio Grande, nas instalações hospitalares da sede municipal ou em Barreiras, município contíguo, cuja cidade é a principal da 
rede urbana regional e que conta, portanto, com serviços médico-hospitalares para necessidades de maior complexidade. No que tange aos serviços educacionais, de igual modo, os estudantes precisam realizar deslocamentos, sendo a maciça maioria encaminhada para o Sítio Grande, onde há escola municipal de Ensino Fundamental, ou para São Desidério, que atende àqueles matriculados no Ensino Médio.

A localidade é servida por energia elétrica, mas não possui fornecimento de água. Para atendimento dessa necessidade, a água é retirada diretamente do rio, seja para o consumo humano, uso doméstico, dessedentação animal e irrigação de pequenas propriedades rurais.

Mais recentemente, como desdobramento da realização da Comitiva dos Matutos (uma cavalgada festiva) e da formação de um Grupo de Jovens, vem sendo gestado um processo embrionário de organização comunitária, com enfoque na preservação das nascentes de pequenos cursos d'água próximos, das áreas remancescentes de cerrado e no enfrentamento ao controle do acesso à água do Rio das Fêmeas exercido pela gestão da pequena central hidrelétrica localizada à montante.

Como já mencionado, o povoado de Penedo está inserido no grande domínio de savana do interior brasileiro, denominado cerrado, e que, segundo Ab'Saber (2003), em sua visão integrada da natureza, pode ser genericamente assim caracterizado:

Quando se atingem as áreas interiores (....), depara-se com o arranjo clássico, homogêneo e monótono da paisagem peculiar às áreas de savana. As formações vegetais talvez não sejam tipicamente de savanas, mas o arranjo e a estrutura de paisagens constituem uma amostra perfeita dos quadros paisagísticos zonais, que caracterizam essa unidade tão frequente do cinturão intertropical do globo.

Nos interflúvios elevados dos "chapadões", onde predominam formas topográficas planas e maciças e solos pobres (latossolo e lateritas), aparecem cerrados, cerradões e campestres, os quais, via de regra, descem até a base das vertentes, cedendo lugar ao fundo aluvial dos vales às florestas-galeria, em geral largas e contínuas (p. 30). (...)

A drenagem superficial da área do cerrado é composta por duas nervuras hidrográficas apenas totalmente integradas durante a estação chuvosa. Há uma drenagem perene, ao fundo dos vales, que responde pela alimentação das florestasgaleria nos intervalos secos. E existe uma trama fina e mal definida de caminhos d'água intermitentes nos interflúvios largos, a qual, associada com a pobreza relativa dos solos, responde pela ecologia do cerrado (p. 30-31).

(...)

A vegetação dos cerrados, tendo se desenvolvido e se adaptado, em algum momento do Quaternário (ou mesmo dos fins do Terciário), a essa estrutura de paisagens, de planaltos tropicais interiorizados dotados de solos lateríticos, é certamente um dos quadros de vegetação mais arcaicos do país (p. 31). 
Contudo, em se tratando do município de São Desidério e, em uma escala ainda mais localizada, de Penedo e seu entorno, o cerrado possui feições particulares, o que, sob alguns aspectos, influencia no modo de vida daquela população, dada a sua estreita relação com os ritmos da natureza, em especial quanto às práticas produtivas.

É a partir da constatação da existência dessa idiossincrasia estabelecida na relação sociedade-natureza que se pretende desenvolver uma proposta de turismo comunitário a partir da ativação do patrimônio biocultural do cerrado no Povoado de Penedo.

A concepção de patrimônio biocultural surge da compreensão quanto à existência de processos de apropriação e uso dos conhecimentos e dos recursos naturais, fundamentada em princípios de equacionamento do desenvolvimento e conservação ambiental (Córdova, 2013). Desde um ponto de vista conceitual, se pode afirmar, concordando com Boege (2001: 1), que patrimônio biocultural diz respeito aos

[...] recursos naturales bióticos intervenidos en distintos gradientes de intensidad por el manejo diferenciado y el uso de los recursos naturales según patrones culturales, los agroecosistemas tradicionales, la diversidad biológica domesticada con sus respectivos recursos fi togenéticos desarrollados y/o adaptados localmente. Estas actividades se desarrollan alrededor de prácticas productivas (praxis) organizadas bajo un repertorio de conocimientos tradicionales (corpus) y relacionando la interpretación de la naturaleza con ese quehacer, el sistema simbólico en relación con el sistema de creencias (cosmos) ligados a los rituales y mitos de origen.

Desta forma, considera-se os patrimônios natural e cultural como fontes potenciais de transformação para comunidades locais, tanto no âmbito simbólicoidentitário e psicossocial, quanto em uma perspectiva material (Ávila, 2013). A ativação do patrimônio biocultural evoca, pois, uma práxis territorial, conforme o sentido que é dado por Marcus Saquet, já mencionado alhures.

Por princípio, o turismo comunitário se faz a partir do reconhecimento e valorização da relação harmônica que uma dada comunidade receptora possui com a natureza ao seu redor e de como tal relação, por um lado, é manifestada por meio de uma cosmovisão própria e, por outra parte, é materializada em saberes e fazeres que integram as formas de reprodução social e econômica a uma longa tradição de uso não predatório dos bens naturais. Aos visitantes interessa, portanto, vivenciar e compreender essa práxis territorial.

Uma análise perfunctória feita na localidade em estudo permitiu levantar alguns elementos que compõem o patrimônio biocultural local como potenciais para dinamizar a prática do turismo comunitário em Penedo, entre os quais, vale destacar: manifestações culturais associadas ao Rio das Fêmeas e ao cerrado, além de práticas agroprodutivas tradicionais ligadas ao cultivo da mandioca e coco e 
manufatura de respectivos subprodutos, coleta de frutos endêmicos do cerrado para produção de doces e sucos e produção artesanal de queijo. Um mapeamento mais profundado certamente fará assomar outros elementos.

No entanto, não se pode romantizar o turismo comunitário como se fora um contato intercultural ingênuo e livre de contradições. Decorre, pois, de toda uma atenção que deva ser dada aos riscos de transformar as comunidades em objeto e não em sujeitos da realização do turismo a necessidade de planejar e gerir tal prática na perspectiva do protagonismo, autonomia e autogestão, conforme é a pretensão dos moradores de Penedo.

\section{O desenho da metodologia}

Por princípio, a metodologia com a qual se pretende desenvolver o trabalho de investigação-intervenção de base cooperativa deve ser construída no transcorrer da sua execução, em etapas subsequentes, em convergência com o aprofundamento das relações de confiança e solidariedade entre comunidade e universidade, primando pela autonomia e saberes populares da primeira e expertise técnico-científica da segunda. Assim, nem todas as etapas estão, desde já, definidas, afinal, como apontado por Acosta (2016: 41), o Buen Vivir é uma "ideia em construção".

Contudo, o início do trabalho, que é uma etapa caracterizada por um maior envolvimento com a pesquisa, requer a observância de planejamento e rigor técnico, permitindo, por um lado, que se tenha disponível um considerável escopo de conhecimentos sobre o povoado de Penedo e sua gente quando da realização das ações da etapa de cooperação, e evitando, por outro lado, que a investigaçãointervenção seja confundida com mera apropriação de conhecimento popular pela academia. Neste sentido, as etapas iniciais de trabalho - que envolvem basicamente o (re)conhecimento e acolhimento mútuos das partes envolvidas e o levantamento de dados sobre a localidade - foram previamente planejadas, como se verá a seguir.

De passagem, vale mencionar, ainda, que este projeto foi concebido a partir da perspectiva de indissociabilidade entre Ensino, Pesquisa e Extensão (Forproex, 2013), de tal modo que, além das ações que são próprias da investigação científica e da interação dialógica de saberes, pretende-se promover, de forma transversal, processos formativos por meio das Oficinas de Formação Comunitária, nas quais serão debatidos temas como Economia solidária e popular, Conservação do cerrado, Associativismo e cooperativismo, Organização comunitária, soberania popular e autonomia, Desenvolvimento Territorial e Turismo comunitário. ${ }^{2}$

2 Importa salientar que esses temas são apenas proposições, cuja decisão final por acrescentar, suprimir, alterar, redefinir e até da não realização dessa atividade será sempre dos moradores locais. 
Isto posto, retoma-se a explicitação da metodologia, expondo, a seguir, as etapas de trabalho e os procedimentos e ferramentas metodológicos. Contudo, conforme já mencionado em outro trecho deste escrito, todo o trabalho aqui proposto está em construção - sob os desígnios da comunidade envolvida - e as etapas - doravante chamadas de "tempos" - aqui evidenciadas serão elaboradas de forma cooperativa e colocadas sob avaliação e validação dos moradores de Penedo antes de serem executadas.

O primeiro tempo, denominado de "(Re)conhecimento e Acolhimento", consiste na criação de um processo de aproximação mútua entre comunidade e universidade, a partir da mediação da Secretaria de Meio Ambiente e Turismo de São Desidério, com o intuito de promover uma convergência de interesses e estabelecer uma relação de confiança e um ambiente de criatividade entre os envolvidos ou, nos termos de Alberich et alli (2009), uma negociação do tema e dos objetivos. Para tanto, faz-se necessária a realização de uma dinâmica de grupo - a Roda de Conversa -, a partir da qual os membros da comunidade e da universidade possam fazer relatos, reflexões e apresentação de seus interesses e demandas.

Uma possibilidade a ser considerada quando da realização da Roda de Conversa é estabelecer distintos momentos nos quais se pode desenvolver tal dinâmica, primeiro, com um grupo maior, formado por todos os membros da comunidade que demonstrem interesse em participar, e, em seguida, com grupos focais, formados por jovens, mulheres, idosos e outros segmentos que venham a ser identificados. Isso pode permitir a identificação de diferentes interesses e/ou conflitos de gênero ou de foro geracional, por exemplo.

Ainda nesse tempo, em um segundo momento, deve-se fazer a apresentação da ideia geral de investigação-intervenção aos membros da comunidade, mas com a devida abertura para o acolhimento de sugestões ou mesmo o rechaço (e o consequente reordenamento de procedimentos) de etapas do trabalho investigativo-cooperativo proposto.

O tempo seguinte, denominado "Sistematização de Conhecimentos", diz respeito à realização do conjunto de atividades investigativas sobre a relação comunidade e natureza a partir do desvelamento de suas territorialidades e temporalidades e tem como objetivo sistematizar e retroalimentar o conhecimento que a comunidade tem de si e do seu território.

Nesse tempo, cabe realizar, por um lado, o chamado "trabalho de gabinete", a partir do qual é possível fazer a identificação, coleta e análise de fontes primárias (documentos pessoais, iconografia, relatórios técnicos, etc.) e secundárias (livros, coletâneas, artigos, etc.) sobre a comunidade, o território e o tema da investigaçãointervenção, além do "trabalho de campo", de onde é possível obter dados localmente situados por meio do emprego combinado e complementar de técnicas como a observação, mapeamento participativo (mapa de atores e cartografia social), ausculta (storytelling, entrevistas, questionários). Ademais, é o momento 
ideal para obtenção de relatos circunstanciados (árvore de problemas), registros de imagens (fotografias e filmagens) e levantamento de dados geoespaciais (GPS).

Uma vez obtido todo esse conjunto de dados, procede-se a sua transformação em informações relevantes para o êxito do tempo seguinte da investigaçãointervenção, que consiste na cooperação entre comunidade e universidade para a implantação do turismo comunitário em Penedo. Para tanto, as ditas informações passam a compor três eixos de conhecimento, quais sejam, (a) a delimitação do povoado de Penedo, segundo o reconhecimento da comunidade quanto à sua dimensão territorial, (b) a caracterização geográfico-histórica da localidade, pondo em relevo os aspectos relativos às territorialidades e temporalidades protagonizadas por seus moradores e (c) a caracterização dos saberes-fazeres locais, tratando de compreender os vínculos entre comunidade e o cerrado, ou seja, a práxis territorial, de modo a induzir processos que levem à ativação do patrimônio biocultural local.

O tempo denominado "Cooperação Comunidade-Universidade" corresponde à fase na qual serão desenvolvidas as atividades cooperativas entre comunidade e universidade, com o intuito de executar a proposta de turismo comunitário em Penedo. Porém, esse tempo não é objeto de análise deste escrito, uma vez que a metodologia a ser empregada será construída e validada pelos moradores de Penedo - com a mediação dos membros da universidade envolvidos na proposta , tão logo os tempos de $(\mathrm{Re})$ conhecimento e Acolhimento e de Sistematização de Conhecimentos tenham sido concluídos.

Indispensável salientar que, em cada tempo da investigação-intervenção, devese promover um encontro entre os envolvidos para a realização de uma devolutiva, bem como da avaliação coletiva dos resultados alcançados, por meio da análise crítico-reflexiva dos êxitos e óbices identificados no transcorrer da execução das atividades.

\section{Considerações finais}

A proposta metodológica aqui apresentada busca estabelecer vínculos duradouros entre comunidade e universidade com o intuito de realizar uma construção coletiva com base na cooperação para a ativação do patrimônio biocultural e este, por sua vez, será o elemento basilar para o desenvolvimento de uma proposta de turismo comunitário no povoado de Penedo, localizado em pleno cerrado baiano.

Como é sobejamente sabido, pensar e agir a partir de uma metodologia é essencial para reduzir substancialmente as possibilidades de erros em todo esforço técnico, científico ou mesmo de planejamento e gestão. Isso é ainda mais importante quando envolve comunidades motivadas a transformarem suas vidas por meio de uma ação solidária, autônoma e cidadã. 
Neste sentido, acredita-se que esta proposta, inspirada na multissecular filosofia de vida do Buen Vivir, contenha potência suficiente para induzir um movimento transformador a partir dos desejos e aspirações de uma comunidade que historicamente constrói sua cultura simbólica e material em íntima relação com os elementos bióticos e abióticos do cerrado, mobilizando todo esse conhecimento acumulado para gerar experiências enriquecedoras para quem venha a visita-los.

\section{Bibliografia}

Ab’Saber, Aziz (2003). Os domínios de natureza no Brasil: Potencialidades paisagísticas. São Paulo, Ateliê, 159 pp.

Acosta, Alberto (2016). O bem viver. Uma oportunidade para imaginar outros mundos. São Paulo, Autonomia Literária, $262 \mathrm{p}$.

Alberich, Tomás et alli (2009). Metodologías participativas: manual. Madrid: Observatorio Internacional de Ciudadanía y Medio Ambiente Sostenible, 91 pp.

Algranati, Santiago; Bruno, Daniela; Lotti, Andrea (2012). Mapear actores, relaciones y territorios: una herramienta para el análisis del escenario social. Cuadernos de Cátedra, n. 3. La Plata: Universidad Nacional de La Plata, 22 pp.

Ares, Pablo; Risler, Julia (2013). Manual de mapeo colectivo: recursos cartográficos críticos para procesos territoriales de creación colaborativa. Buenos Aires: Tinta Limón, 84 pp.

Arias Llumiquinga, María Cristina (2015). La cartografía técnica y la cartografía social: dos propuestas metodológicas para el diagnóstico territorial. Una experiencia de mapeo participativo en la Parroquia Amaguaña. Tesís de maestría en Estudios Socioambientales, Departamento de Desarrollo, Ambiente y Territorio, Quito: Facultad Latinoamericana de Ciencias Sociales, $132 \mathrm{pp}$.

Ávila Romero, León Enrique (2013). La disputa por el patrimonio biocultural, la economía verde e sus impactos en los pueblos indígenas. Carámbula Pareja, Matías; Ávila Romero, León Enrique (coords.), Patrimonio biocultural, territorio y sociedades afroindoamericanas en movimiento, Buenos Aires: Consejo Latinoamericano de Ciencias Sociales, pp. 31-50.

Bisio, Natalia; Noboa, Alejandro (2019). Algunas reflexiones sobre la construccion de la política en los procesos de participación. Paño Yáñez, Pablo; Rébola, Romina; Suárez Elías, Mariano (comp.), Procesos y metodologías participativas: reflexiones y experiencias para la transformación social, Montevideo: Consejo Latinoamericano de Ciencias Sociales, pp. 209-233.

Boege Schmidt, Eckart (2008). El patrimonio biocultural de los pueblos indígenas de México, Ciudad de México: Instituto Nacional de Antropología e Historia, 344 pp.

Boff, Leonardo (2012). Sustentabilidade: o que é, o que não é. Petrópolis: Vozes, 200 pp.

Brandão, Paulo Roberto Baqueiro (2014). Territórios do turismo, territórios de todos? Um estudo comparado sobre urbanização e formação de territórios em balneários turísticos do Nordeste do Brasil, Curitiba: CRV, 255 pp.

Córdova, Juan Pohlenz (2013). "La disputa por el patrimonio biocultural. Un acercamiento desde Mesoamérica”. Carámbula Pareja, Matías; Ávila Romero, León Enrique 
(coords.), Patrimonio biocultural, territorio y sociedades afroindoamericanas en movimiento, Buenos Aires: Consejo Latinoamericano de Ciencias Sociales, p. 17-30.

Brasil, República Federativa do (2007). Decreto n. 6.040/2007, que institui a Política Nacional de Desenvolvimento Sustentável dos Povos e Comunidades Tradicionais. Brasília: Presidência da República, 2 pp.

Brasil, República Federativa do (2013). Plano Nacional de Agroecologia e Produção Orgânica 2013-2015, Brasília: Ministério do Desenvolvimento Agrário, 5 pp.

Brasil, República Federativa do (2016). Brasil Agroecológico: Plano Nacional de Agroecologia e Produção Orgânica 2016-2019, Brasília: Ministério do Desenvolvimento Agrário, 90 p.

Diez Tetamanti, Juan Manuel (org.) (2014). Hacia una Geografía Comunitaria. Abordajes desde cartografía social y sistemas de información geográfica. Comodoro Rivadavia: Editorial Universitaria de la Patagonia, 163 pp.

Diez Tetamanti, Juan Manuel (2018a). Cartografía social, cartografías y multiplicidad. Producir método desde las trayectorias en la Patagonia Central. +E - Revista de Extensión Universitaria, 9(8), 145-156, Universidad Nacional del Litoral, Santa Fé.

Diez Tetamanti, Juan Manuel (2018b). Cartografía Social: teoria y método. Estrategias para una eficaz transformación comunitária, Buenos Aires: Byblos, 102 pp.

Fals Borda, Orlando (1999). Origenes universales y rectos actuales de la IAP (Investigación Acción Participativa). Análisis Político (38), 71-88, Universidad Nacional de Colombia, Bogotá.

Forproex (Fórum de Pró-Reitores de Extensão das Instituições Públicas de Educação Superior Brasileiras) (2013). Política Nacional de Extensão Universitária, Porto Alegre: Universidade Federal do Rio Grande do Sul, 108 pp.

Freire, Paulo (1982). Extensão ou comunicação?, Rio de Janeiro: Paz e Terra, 143 pp.

Freire, Paulo (2013). Pedagogia da autonomia. Saberes necessários à prática educativa, São Paulo: Paz e Terra, 93 pp.

Harvey, David (2005). O neoliberalismo. História e implicações, São Paulo: Loyola, 249 p.

Montañez Gómez, Gustavo (2001). Introducción: razón y pasión del espacio y el territorio. Montañez Gómez, Gustavo y otros (ed.), Espacio e territórios. Razón, pasión e imaginarios, Bogotá: Editorial de la Universidad Nacional de Colombia, pp. 15-32.

Pignante, Elisa; Dansero, Egidio; Loda, Mirella (2015). Geografia e cooperazione allo sviluppo: prospettive e agende di ricerca. Geotema, XIX(48), 5-24, Associacione dei Geografi Italiani, Roma.

Sabourin, Eric; Niederle, Paulo (2017). Agricultura familiar Na América Latina: das políticas agrícolas diferenciadas aos instrumentos de promoção da soberania e segurança alimentar e nutricional e da agroecología. Maluf, Renato; Flexor, Georges (org.) Questões agrárias, agrícolas e rurais: conjunturas e políticas públicas, Rio de Janeiro: EPapers, p. 270-286.

Schavelzon, Salvador (2015). Plurinacionalidad y Vivir Bien/Buen Vivir. Dos conceptos leídos desde Bolivia y Ecuador post-constituyentes, Quito: Abya-Yala, 286 pp.

Santos, Milton (2002). A natureza do espaço, São Paulo: Editora da Universidade de São Paulo, $384 \mathrm{pp}$.

Santos, Milton (2008). Por uma outra globalização. Do pensamento único à consciência universal, Rio de Janeiro: Record, $176 \mathrm{pp}$. 
Saquet, Marcos Aurélio (2015). Por uma Geografia das territorialidades e das temporalidades: uma concepção multidimensional voltada para a cooperação e para o desenvolvimento territorial, Rio de Janeiro: Consequência, $162 \mathrm{pp}$.

Saquet, Marcos Aurélio (2019). Saber popular, práxis territorial e contra-hegemonia. Rio de Janeiro: Consequência, $141 \mathrm{pp}$.

Tapella, Esteban (2007). El mapeo de actores claves. Documento de trabajo del proyecto Efectos de la biodiversidad funcional sobre procesos ecosistémicos, servicios ecosistémicos y sustentabilidad en las Américas: un abordaje interdisciplinario, Córdoba: Universidad Nacional de Córdoba, 18 pp. 